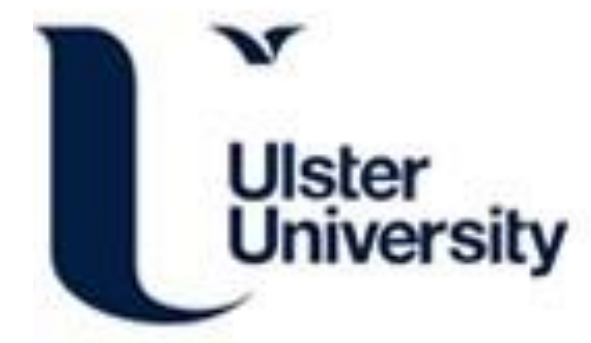

\title{
Selective serotonin reuptake inhibitor antidepressant use in first trimester pregnancy and risk of specific congenital anomalies: A European register-based study
}

Wemakor, A., Casson, K., Garne, E., Bakker, M., Addor, M-C., Arriola, L., Gatt, M., Khoshnood, B., Klungsoyr, K., Nelen, V., O'Mahony, M., Pierini, A., Rissmann, A., Tucker, D., Boyle, B., de Jong-van den Berg, L., \& Dolk, H. (2015). Selective serotonin reuptake inhibitor antidepressant use in first trimester pregnancy and risk of specific congenital anomalies: A European register-based study. European Journal of Epidemiology, 30(11), 1187-1198. https://doi.org/10.1007/s10654-015-0065-y

Link to publication record in Ulster University Research Portal

Published in:

European Journal of Epidemiology

Publication Status:

Published (in print/issue): 30/11/2015

DOI:

10.1007/s10654-015-0065-y

\section{Document Version}

Author Accepted version

\section{General rights}

Copyright for the publications made accessible via Ulster University's Research Portal is retained by the author(s) and / or other copyright owners and it is a condition of accessing these publications that users recognise and abide by the legal requirements associated with these rights.

\section{Take down policy}

The Research Portal is Ulster University's institutional repository that provides access to Ulster's research outputs. Every effort has been made to ensure that content in the Research Portal does not infringe any person's rights, or applicable UK laws. If you discover content in the Research Portal that you believe breaches copyright or violates any law, please contact pure-support@ulster.ac.uk. 
Selective Serotonin Reuptake Inhibitor Antidepressant Use in First Trimester

Pregnancy and Risk of Specific Congenital Anomalies: A European Register-based

\section{Study}

Wemakor Anthony, Centre for Maternal, Fetal and Infant Research, Institute of Nursing and Health Research, University of Ulster, UK, \& School of Allied Health Sciences, University for Development Studies, Tamale, Ghana, $(\mathrm{PhD})$;

Casson Karen, Centre for Maternal, Fetal and Infant Research, Institute of Nursing and Health Research, University of Ulster, UK, (PhD);

Garne Ester, Hospital Lillebaelt, Kolding, Denmark, (MD);

Bakker Marian K, Eurocat Northern Netherlands, Department of Genetics. University of Groningen, University Medical Center Groningen, The Netherlands, (PhD);

Addor Marie-Claude, Service of Medical Genetics CHUV Lausanne, Switzerland, (MD); Arriola Larraitz, Public Health Division of Gipuzkoa, Instituto BIO-Donostia, Basque Government, CIBER Epidemiología y Salud Pública - CIBERESP, Spain, (MD);

Gatt Miriam, Department of Health Information and Research, Guardamangia, Malta, (MD); Khoshnood Babak, Paris Registry of Congenital Malformations, INSERM U953, France (MD, PhD);

Klungsoyr Kari, Medical Birth Registry of Norway, Norwegian Institute of Public Health, Norway, and Department of Global Public Health and Primary Care, University of Bergen, Norway (MD, PhD);

Nelen Vera, Provinciaal Instituut voor Hygiene, Antwerp, Belgium, (MD);

O’Mahoney Mary, Health Service Executive, Cork, Ireland, (MD);

Pierini Anna, Unit of Epidemiology, IFC CNR (Tuscany Registry of Birth Defects), Pisa, Italy, (BSc); 
Rissmann Anke, Malformation Monitoring Centre, Medical Faculty Otto-von-GuerickeUniversity Magdeburg, Germany, (MD);

Tucker David, Congenital Anomaly Register \& Information Service, Public Health Wales, UK, (MPH);

Breidge Boyle Centre for Maternal, Fetal and Infant Research, Institute of Nursing and Health Research, University of Ulster, UK, $(\mathrm{PhD})$;

de Jong-van den Berg LTW, Department of Pharmacy, University of Groningen, (PhD);

Dolk Helen, Centre for Maternal, Fetal and Infant Research, Institute of Nursing and Health Research, University of Ulster, UK, (DrPH).

\section{Corresponding author:}

Prof Helen Dolk

WHO Collaborating Centre for the Epidemiologic Surveillance of Congenital Anomalies Room 12L23

Centre for Maternal, Fetal and Infant Research

Institute of Nursing and Health Research

Ulster University, Shore Road

Newtownabbey, United Kingdom

BT37 0QB

Tel: +44 2890368540

Email: $\underline{\text { H.Dolk@ulster.ac.uk }}$

Keywords: congenital anomaly, SSRI, medication, depression, epidemiology, registry 


\section{Abstract}

Evidence of an association between early pregnancy exposure to Selective Serotonin Reuptake Inhibitors (SSRI) and congenital heart defects (CHD) has contributed to recommendations to weigh benefits and risks carefully. The objective of this study was to determine the specificity of association between first trimester exposure to SSRIs and specific CHD and other congenital anomalies (CA) associated with SSRI exposure in the literature (signals). A population-based case-malformed control study was conducted in 12 EUROCAT CA registries covering 2.1 million births 1995-2009 including livebirths, fetal deaths from 20 weeks gestation and terminations of pregnancy for fetal anomaly. Babies/fetuses with specific CHD $(n=12,876)$ and non-CHD signal CA $(n=13,024)$, were compared with malformed controls whose diagnosed CA have not been associated with SSRI in the literature $(n=17,083)$. SSRI exposure in first trimester pregnancy was associated with CHD overall (OR adjusted for registry 1.41, 95\% CI 1.07-1.86, fluoxetine adjOR 1.43 95\% CI 0.85-2.40, paroxetine adjOR 1.53, 95\% CI 0.91-2.58) and with severe CHD (adjOR 1.56, 95\% CI 1.022.39), particularly Tetralogy of Fallot (adjOR 3.16, 95\% CI 1.52-6.58) and Ebstein's anomaly (adjOR 8.23, 95\% CI 2.94-23.16). Significant associations with SSRI exposure were also found for anorectal atresia/stenosis (adjOR 2.46, 95\% CI 1.06-5.68), gastroschisis (adjOR 2.42, 95\% CI 1.10-5.29), renal dysplasia (adjOR 3.01, 95\% CI 1.61-5.61), and clubfoot (adjOR 2.41, 95\% CI 1.59-3.65). These data support a teratogenic effect of SSRIs specific to certain anomalies, but cannot exclude confounding by indication or associated factors. 


\section{Introduction}

In Europe, between 3\% and 11\% of women have been estimated to have major depression in any one year [1-4]. Untreated depression in pregnancy impacts negatively on both the mother and the developing fetus, increasing the risk of premature delivery, low birth weight, small for gestational age and child developmental outcomes [5-6]. Pharmacotherapy is a popular treatment approach but the safety in pregnancy of most antidepressant medications is uncertain [7]. Therefore, guidelines recommend that pharmacotherapy should be avoided if possible in pregnancy in favour of non-pharmaceutical treatments except in the case of severe depression where benefits outweigh risks [8]. However, the critical period of organogenesis is early in pregnancy and pregnancies may be inadvertently exposed to antidepressant medication before women become aware they are pregnant, or there may not be sufficient time to change medication or treatment approach for women receiving treatment for depressive disorders who become pregnant.

Antidepressant use in first trimester pregnancy has been estimated at 2.0-10.0\% [9-14]. Selective Serotonin Reuptake Inhibitor (SSRI) antidepressants are widely prescribed for treating major depression, including in pregnancy [13-16]. Prior to 2005, SSRIs were regarded to be safe in pregnancy, based mostly on prospective cohort studies with limited sample sizes [17-21]. Thereafter, starting with paroxetine [22], the SSRIs have come under scrutiny particularly in relation to congenital heart defects (CHD) [22-37]. Although not all studies have supported this association [38-45], meta-analyses have found positive overall evidence [46-50]. Some non-CHD congenital anomalies have also been linked to SSRI exposure in first trimester pregnancy [24, 29, 32, 34-35] although this literature is much smaller. Inconsistencies in the literature can be expected due to different sources of bias, for 
example the non-inclusion of terminations of pregnancy for fetal anomaly in many studies, different levels of accuracy in recording the diagnosis of CHD and other CA, use of different exposure window definitions [51] and small study population sizes which have meant that statistically significant risks appear to relate to the more common congenital anomalies (such as septal heart defects) or the more commonly used SSRIs.

The biologic plausibility of a teratogenic effect of SSRIs in humans is based on studies of drug and metabolite levels in amniotic fluid and cord blood combined with evidence from animal studies [52]. Most SSRIs have a short half-life (approximately 1 day). Fluoxetine has a half-life of approximately 1-4 days and its metabolite norfluoxetine a half-life of 7-15 days [53]. Serotonin acts as an important signalling molecule in progenitor heart cells during the establishment of laterality, formation of the outflow tract, myocardial cell differentiation, and septation of the heart chambers [54] and abnormal levels during these critical periods e.g., through the activity of serotonin reuptake inhibitors, has been shown to lead to faulty morphogenesis in animal models [55-56].

There remains, however, some controversy about the nature of the causal association in human epidemiological studies. It has been suggested that the apparent excess risk of less severe CHDs might reflect ascertainment bias due to greater likelihood of exposed babies receiving special neonatal care [48, 57-58]. Other studies have focused on confounding by indication or co-exposures including co-medications [23, 33, 59] finding evidence of attenuation of CHD risk.

European Surveillance of Congenital Anomalies (EUROCAT) is a large congenital anomaly surveillance system [60] with a central database which has previously been used to study 
risks of antiepileptic drug exposure [61]. Using the considerable statistical power provided, we examined the specificity of association between first trimester exposure to SSRIs and specific CHD and non-CHD anomaly subgroups.

\section{Materials and Methods}

Study design

Case-malformed control study based on EUROCAT population-based congenital anomaly registries. Cases were babies with CHD, or with congenital anomalies other than CHD identified as significantly associated with SSRI exposure ("signals”) in at least one previous study. Controls were all other registrations. Genetic conditions were excluded from both cases and controls.

\section{Setting and Data Source}

EUROCAT registries were included if they had a recorded antidepressant exposure of at least 3 per 1000 and at least 5 exposed registrations in designated 5 year periods: 1995-1999, 2000-2004, 2005-2009. 12 registries in 12 European countries were included for all or part of 1995-2009 (Table 1). The data from Northern Netherlands registry 1997-2006 have been previously published limited to paroxetine use [36]. The 12 registries registered 70,117 babies/fetuses with congenital anomaly from a population of 2,177,977 births. Data were extracted from the central database of EUROCAT [60]. EUROCAT registries collect data on live births, stillbirths and late fetal deaths from 20 weeks gestation, and terminations of pregnancy for fetal anomaly (TOPFAs). Registries use multiple sources of information: maternity, neonatal, and paediatric records; fetal medicine, cytogenetic, pathology, and medical genetics records; paediatric cardiology services; and hospital discharge and child health records [62]. Eleven of the 12 registries register children with 
congenital anomalies up to age one year or more. A registrant can have up to 8 malformations and one syndrome recorded. Congenital anomalies are coded to the International Classification of Diseases (ICD) version 9 or 10 with 1-digit BPA extension. These codes are classified into the standard EUROCAT malformation subgroups [63] (see Appendix). The severe CHD subgroup as defined by EUROCAT included all CHD subgroups with higher perinatal mortality (see Appendix) [64]. Babies/fetuses with only congenital anomalies categorised as minor according to EUROCAT definitions were excluded [63].

\section{Cases and controls}

Cases and controls were defined as livebirths, fetal deaths from 20 weeks, and terminations of pregnancy for fetal anomaly following prenatal diagnosis with non-genetic major CA. 7,813 genetic registrations (chromosomal or single gene disorders) identified using the EUROCAT multiple malformation algorithm [65] were excluded as having a different preconceptional aetiology [66-67]. 201 cases/controls with teratogenic syndromes were also excluded as of known cause. To avoid terminological confusion, we refer to any baby with congenital anomaly as a "registration”, covering both cases and controls and excluded babies.

Cases of CHD: ICD codes Q20-26 (ICD10) and 745, 746, and 7470 to 7474 (ICD9-BPA), with or without extra-cardiac anomalies. Excluded from CHD were preterm deliveries $(<37$ weeks) with only patent ductus arteriosus (Q250 or 7470), and all cases with only patent foramen ovale (Q2111) [62]. CHDs were classified into EUROCAT CHD subgroups [63] (see Appendix). 
Cases of non-CHD "signals": Cases were 13 standard EUROCAT congenital anomaly subgroups (and organ system subgroups including those anomalies) which had shown statistically significant associations with one or more SSRI types in the literature (accessed via Pubmed and Embase up to June 2012) [24, 29, 32, 34-35]:

Neural tube defects - paroxetine [35]

anencephaly (part of neural tube defects) - SSRI, paroxetine [34]

eye defects - paroxetine [24]

ear/face/neck defects - fluoxetine [32]

respiratory defects - sertraline [32]

digestive system defects - fluoxetine [32]

anorectal atresia and stenosis (part of digestive system) - sertraline [35]

gastroschisis - paroxetine [34]

omphalocele - SSRI, paroxetine, sertraline [34-35]

renal dysplasia - SSRI [29, 32]

hypospadias - paroxetine [29]

limb reduction - sertraline [35]

lower limb reduction (part of limb reduction) - SSRI [32]

clubfoot - SSRI, paroxetine [35]

craniosynostosis [34]

Cases where any of the above were associated with CHD were analysed only as CHD cases.

Controls. Controls were the remaining congenital anomaly registrations, after excluding all registrations with CHD or with a non-CHD “signal” congenital anomaly subgroup. 
An exploratory analysis was conducted within the control group to determine whether any of the component anomalies were more commonly exposed to SSRI than other controls, adjusting odds ratios for registry.

\section{Exposure ascertainment}

For the most part, our medication exposure information came from maternal medical/midwifery notes, created prospectively [68]. Other additional data sources include paediatrician records (postnatal), medical geneticist records (postnatal), GP records of mother (prenatal), and maternal interviews (postnatal) (see Table1). One registry accesses a prescription database as its primary source and verifies use of prescribed medications through postnatal telephone interviews with the mothers. Data sources per registry are shown in Table 1. Data sources were unbiased with respect to case/control status. Medication exposure was ascertained similarly for all types of pregnancy outcomes, except for one registry which did not obtain medication data for TOPFA (TOPFA for that registry were excluded from the dataset). Drug data are coded to the Anatomical Therapeutic Chemical (ATC) code [69]. Maternal illness before and during pregnancy is coded to ICD codes (ICD-9 or ICD-10).

Exposure was defined as use of SSRI (ATC N06AB) without use of any other type of antidepressant. The first trimester of pregnancy was defined as the period from the first day of the last menstrual period up to the 12th week of gestation [63]. Women were excluded from the dataset if they took non-SSRI antidepressants $(n=121)$ or unspecified antidepressants ( $\mathrm{n}=39$ ), and for the specific SSRI analyses, if they took more than one specific SSRI ( $n=1$, citalopram + fluoxetine). Women were considered unexposed if the registry did not record use of any antidepressants in first trimester pregnancy. When using maternity records to ascertain medication usage, it is not always possible to distinguish no 
usage of the medication from no reported usage - unknown medication use mainly indicated that the sources of medication information for the case were not available to the register, while no exposure indicated that the usual sources had been consulted but no exposure was recorded. Two registries (Antwerp and Tuscany) did not distinguish these two situations, and all of their cases without recorded exposure were considered unexposed. Six SSRI antidepressants were recorded: Fluoxetine (N06AB03), Citalopram (N06AB04), Paroxetine (N06AB05), Sertraline (N06AB06), Fluvoxamine (N06AB08), and Escitalopram (N06AB10). All were analysed individually except Fluvoxamine to which only six women were exposed. Where a significant association was found, exposed cases were checked with registries to verify first trimester exposure and drug type, and these case lists were also examined for evidence that co-exposure to other medications might constitute a significant source of confounding. The Atrial Septal Defect (ASD) cases exposed to SSRIs were in addition checked with the registries to determine whether they had been infants in specialist neonatal care who may have been examined more intensively, which could lead to diagnostic bias.

To avoid misclassification of antidepressant exposure status, women with drug use unknown or missing ( $n=17,869$, including all TOPFA from one of the registries) or those with a record of depression diagnosis with no record of antidepressant use $(n=20)$ were excluded. To avoid confounding by co-exposure to identifiable teratogenic medications/condition, cases/controls were excluded if they had a record of exposure to antiepileptic medication ( $n=374)$, or antidiabetic medication/diabetes $(n=697)$, or they had teratogenic syndromes $(n=201)$.

After all exclusions, the study was based on the remaining 42,983 registrations. 


\section{Statistical analysis}

Logistic regression analysis was used to estimate Odds Ratios and 95\% confidence intervals using Stata version 9.0 (Statacorp LP, College Station, TX, USA). Analysis was limited to congenital anomaly subgroups with at least 3 exposed cases as it was considered that odds ratios based on 1 or 2 cases could not be meaningfully interpreted. In cases where a statistically significant association was detected between SSRI (combined) and any congenital anomaly subgroup, results for specific SSRIs are presented even when the number of exposed cases was less than 3 to facilitate assessment of specificity of association between specific SSRIs and specific congenital anomalies. Analyses were adjusted for registry in order to adjust for confounding that may arise if registries differ in both exposure and outcome prevalences. As recommended for observational epidemiological studies, no statistical adjustment was performed for multiple testing [70], but design and interpretation took into account presence of a prior hypothesis.

Ethics approval: EUROCAT has approval from the University of Ulster Research Ethics Committee. Additionally, all registries have ethical approval appropriate to their national and local ethics guidelines.

\section{Results}

A total of 42,983 non-genetic congenital anomaly registrations consisting of 12,876 with CHD, 13,024 with one or more of the 15 "signal” subgroups, and 17,083 controls were included in the analysis. Exposure to SSRIs in first trimester pregnancy among all registrations was $0.76 \%(328 / 42,983)$ (Table 1$) ; 0.68 \%$, and $0.66 \%$ of the CA registrations were exposed to SSRI in 1995-1999 and 2000-2004 respectively with the exposure increasing to $0.90 \% 2005-2009\left(\chi^{2}=7.65, \mathrm{df}=2, \mathrm{p}=0.022\right)$. By type of birth, $0.76 \%$ of livebirths, $0.79 \%$ 
of TOPFA and $0.87 \%$ of stillbirths were exposed to SSRI $\left(\chi^{2}=0.11, \mathrm{df}=2, \mathrm{p}=0.945\right) .14 .6 \%$ of the women who had SSRI prescriptions also had prescriptions for psycholeptic medications.

Among the controls, 99 registrations were exposed to SSRIs, of which 27 were to fluoxetine, 27 to paroxetine, 20 to citalopram, 14 to sertraline, 9 to escitalopram and one to fluvoxamine.

\section{Congenital Heart Defects}

SSRI (combined) exposure was significantly associated with CHD (OR 1.41, 95\% CI 1.071.86, Table 2); the association was similar or slightly stronger for severe CHD (OR 1.56, 95\% CI 1.02-2.39, Table 2) while the association with the main other CHD group, septal defects, was slightly lower and of borderline statistical significance (OR 1.36, 95\% CI 0.991.87, Table 2). Assessing specific SSRIs for CHD combined, the raised odds does not appear to be specific to any one SSRI - odds ratios were between 1.43 and 1.53 with overlapping confidence intervals for the four most common SSRIs, and a lower OR with a wide confidence interval was found only for escitalopram (OR 1.10, 95\% CI 0.41-2.95). Assessing specificity of association for specific SSRIs and severe CHD also did not reveal raised odds limited to any one SSRI (Table 2).

Statistically significant associations were detected between SSRI and Tetralogy of Fallot (TOF) (OR 3.16, 95\% CI 1.52-6.58, 8 exposed cases, Table 2). The TOF association was not limited to any one specific SSRI (Table 2).

The strongest association with SSRI exposure was for Ebstein's anomaly (OR 8.23, 95\% CI 2.92-23.16), with 4 exposed cases distributed across 4 different types of SSRIs. Examination 
of the exposed case list showed that no cases were co-exposed to lithium. Although the strongest evidence for severe CHD types was for TOF and Ebstein's anomaly, other subgroups either showed non-significant raised odds ratios (e.g. Atrioventricular septal defect with OR 2.08) or odds ratios closer to 1 but with wide confidence intervals.

The association between SSRIs and septal defects was of borderline significance (Table 2). Odds ratios were generally higher for the septal defect subtype ASD (OR 1.71, 95\%CI 1.092.68, Table 2) than VSD, except for a VSD-paroxetine association (OR 1.90, 95\%CI 1.043.48, Table 2). Among the 25 SSRI exposed ASD cases, 7 were in neonatal intensive units, 5 were not and there is no information on the remaining 13 infants.

\section{Non-CHD signals}

There were 121 SSRI exposed babies with anomalies belonging to the 15 "signal” subgroups (Table 3). For five of these subgroups, a statistically significant association was found with SSRI combined, or a specific SSRI type. Exposure to SSRI was associated with increased odds of ano-rectal atresia and stenosis (OR 2.46, 95\% CI 1.06-5.68, Table 3), but there were no exposures to sertraline, the origin of the signal (Table 3).

Gastroschisis was associated with SSRI exposure (OR 2.42, 95\% CI 1.10-5.29, Table 3), but was associated with other SSRI than paroxetine (Table 3).

Renal dysplasia was associated with SSRI exposure (OR 3.01, 95\% CI 1.61-5.61, Table 3), particularly fluoxetine (OR 5.76, 95\% CI 2.54-13.08). 
A significant association was found between hypospadias and citalopram (OR 3.21, 95\% CI

1.56-6.60, Table 3), while a non-significant modestly elevated OR of 1.34 (95\% CI 0.58-

3.09) was found with paroxetine (Table 3).

Clubfoot was associated with SSRI exposure (OR 2.41, 95\% CI 1.59-3.65), particularly with paroxetine, sertraline and escitalopram where point estimates were close to or above 3.

The OR for SSRI and craniosynostosis was of borderline statistical significance (OR 2.48, 95\% CI 0.99-6.22). Odds ratios close to one were found for neural tube defects, anencephaly, and eye, ear/face/neck, respiratory system defects, digestive system defects, and limb reduction defects (Table 3). There were less than 3 exposed cases of omphalocele which was not analysed separately.

Subgroups included within the controls

There were 99 SSRI exposed controls. Eleven EUROCAT subgroups had at least 3 SSRI exposed registrations and were analysed in comparison with all other controls combined. A statistically significant association was observed for SSRI and microcephaly (OR 4.15, 95\% CI 1.60-10.78) with 5 cases distributed across 4 SSRI types (online appendix).

Sensitivity analyses in which women with missing/unknown drug exposure were classified with the unexposed group yielded comparable odds ratios to those reported in the main analysis. We did not formally take into account multiple pregnancies per woman in the statistical analysis. However, we looked for twin and sibling pairs among the SSRI exposed. We found three sets of sibling/twin pairs whose mothers were exposed to SSRI. One set of twins had very different congenital anomalies (one non-severe cardiac, one genital), one set 
of siblings born 10 years apart and exposed to different SSRI both had isolated congenital hip dislocation and one sibling pair born one year apart with the same exposure, both had CHD anomalies one of which was a severe CHD. Taking siblings into account therefore does not change the results substantially.

\section{Discussion}

This is the first study to have systematically examined the full range of congenital anomalies in a large population. We found a statistically significant association between SSRIs as a class and CHD overall supporting previous reports of this association [22-37, 46-47, 68]. We have been able to show in addition that the association is stronger for severe CHD and, therefore, is unlikely to be explained as neonatal examination bias or more frequent echocardiograms or other screening/diagnostic procedures for SSRI exposed infants [48, 5758]. We have also shown that the association is not specific to any one SSRI type, although the power of the study to estimate differences between the effects associated with specific SSRIs was limited. This suggests switching from one specific SSRI to another before or in pregnancy is not an effective strategy to reduce the risk of CHD. Our finding of nonspecificity by SSRI type is compatible with the mechanism of teratogenic action being one that is common to all SSRIs and is also compatible with confounding by depression as indication or other associated factors/exposures.

Recent studies have suggested that the association between SSRI and CHD may be explained by confounding $[23,33,59]$. A Danish healthcare database study of livebirths found a higher risk of CHD both among women exposed to SSRI in the first trimester, and those who paused SSRI use during pregnancy, suggesting confounding by underlying depression or factors 
associated with depression [33]. A British healthcare database study of livebirths found a small excess risk of CHD (14\%) with SSRI exposure, and a similarly small excess risk (10\%) for women with unmedicated depression, and for individual SSRIs found a significantly elevated risk only for paroxetine when compared to unmedicated depression [23]. A US health insurance database study found that in an analysis restricted to women with a diagnosis of depression, controlling for co-exposures to other medications attenuated the CHD risks [59]. In our study we did not have full information on depression diagnosis, but we excluded women with diabetes/insulin or antiepileptic exposures where the main risk of confounding lies and, since the numbers of exposed cases are very small for statistical adjustment for confounding by co-medication, we examined case lists for evidence of potential confounding by co-medications and found none. We also used validated registry CA diagnoses, including TOPFA, rather than relying on the problematic recording of CA in healthcare databases [71]. Further investigation of the hypothesis that the causal association is with the underlying depression is necessary, taking into account the specificity we find in relation to types of CHD and other CA. Moreover, the evidence that maternal depression increases congenital anomaly risk is lacking [6], although there are known associations with stress [72], and this requires further research.

We found previously unreported associations between SSRI and Tetralogy of Fallot (OR 3.16, 95\% CI 1.52-6.58) and Ebstein's anomaly (OR 8.23, 95\% CI 2.92-23.16). The finding relating to Ebstein's anomaly is of particular interest given that it has previously been reported to be associated with the antipsychotic drug lithium [73] which has led to avoidance of lithium use in pregnancy, although the evidence remains controversial [74]. None of the SSRI exposed Ebstein's anomaly cases in our data also had lithium exposure and the SSRI association appears to be an independent finding. 
Our findings support an association between SSRIs and ASD, but we found no evidence that this was specific to paroxetine as previously reported [32-33] and we did find some evidence that exposed cases of ASD tended to have been cared for in neonatal units and thus biased ascertainment of ASD is possible. We found a previously unreported association between paroxetine and VSD, which did appear to be specific only to paroxetine.

Among 15 non-CHD signals in the literature, 5 were supported by statistically significant associations with odds ratios above 2 in our data (ano-rectal atresia and stenosis, gastroschisis, renal dysplasia, clubfoot and hypospadias). Craniosynostosis was also of borderline significance. Except for hypospadias, these associations were not confined to any one SSRI, and often not the SSRI type of the original signal [24, 29, 32, 34-35].

Gastroschisis, is strongly associated with socio-economic deprivation and lifestyle exposures, including smoking and recreational drugs [75], and confounding or cumulative or interacting exposure effects should also be considered as an explanation for its association with SSRI use. For other anomalies, the evidence concerning factors such obesity [76], smoking [77], and alcohol use [78] would suggest that confounding would be unlikely to be strong enough to explain odds ratios above 2 .

For the other signal subgroups (neural tube defects/anencephaly, eye, ear/face/neck, respiratory system, digestive system, omphalocele, limb reduction) our data do not support associations with SSRI, but generally wide confidence intervals cannot exclude moderate associations. Folic acid could have been an unmeasured confounder in our analyses - the absence of an association between SSRI and neural tube defects (the congenital anomaly most strongly associated with folic acid), suggests that either SSRI users are as likely to use 
folic acid as other mothers, or that SSRI users take more folic acid but folic acid protects against the teratogenic effects of SSRI.

The finding in the exploratory analysis of a significant association with microcephaly is of interest given the wide range of teratogenic exposures associated with microcephaly [79] but confounding and the likelihood of spurious chance associations due to multiple testing mean that this should be very cautiously interpreted until confirmed by other studies.

\section{Strengths and limitations}

This study has several strengths. It used data from a large population-based congenital anomaly surveillance system covering approximately 2 million births in 12 European countries providing the opportunity to study some rare CHD types and other congenital anomalies. Importantly, the database has information on TOPFA following prenatal diagnosis which constituted about 5.9\% of all (non-genetic) registrations, a much higher proportion for more severe CAs. Inclusion of TOPFA is particularly important since uptake of prenatal diagnosis and TOPFA may be associated with depression, SSRI use or socioeconomic correlates. For most of the registries, exposure data were recorded prospectively before outcome was known eliminating the possibility of recall bias, but in addition the use of malformed controls meant that there was little opportunity for recall bias.

The main limitation of the study relates to exposure classification. There was undoubtedly underascertainment of antidepressant use, as shown by the relatively low exposure prevalence of $0.8 \%$ overall, when compared to population-based estimates among pregnant women [9, 12-15, 79]. SSRI exposure is difficult to ascertain accurately, and even comparisons between research birth cohorts and prescription databases have shown considerable unexplained 
discrepancies [51, 80]. One quarter of registrations had missing exposure information. While there is no reason to believe this exposure misclassification was differential across cases and controls and thus would lead to bias, the low exposure prevalence did decrease the statistical power of the study. There was no information on dosage or length of exposure to SSRIs Berard et al [37] suggested that the teratogenic effect of paroxetine may be limited to higher doses (25mg/day). We assumed, as is customary, that the relevant exposure window was the first trimester (as these are the available EUROCAT data) but this window is wider than the sensitive period for many congenital anomalies, some congenital anomalies may occur after later exposures [81]. On the other hand, some of the exposures recorded do not specify timing precisely and may be misattributed to the first trimester, although we verified timing for anomalies where significant associations were found. In general, misclassification of exposure is likely to have led to underestimation of odds ratios.

Use of malformed controls could lead to underestimation of the odds ratio if the SSRIs under study also caused malformations that are included in the controls. However, by design, we excluded all known non-CHD "signals” from the control group and an exploratory analysis carried out on the control group found only one anomaly subgroup (microcephaly) to be disproportionately represented among the SSRI exposed. We excluded chromosomal syndromes from both cases and controls. Further research could examine whether a fetus with a chromosomal syndrome has a greater sensitivity to the teratogenic effect of SSRIs, but our study did not have the statistical power to do this.

Multiple comparisons were carried out and some of the significant associations might be due to chance, although we tried to minimise this problem by clear specification of prior 
hypotheses. Data were unavailable on possible confounding co-exposures as already discussed.

\section{Implications for Practice}

Our data cannot resolve whether the association between SSRI use and congenital anomalies is a causal one. We have however been able to show the range of congenital anomalies associated with SSRI use includes severe CHD and also goes beyond CHD, we have estimated the strength of association for each anomaly, and shown that the risks are found across a range of specific SSRI types. In a population of 100,000 pregnant women, of whom 4\% [14] take SSRIs during the first trimester (4,000 women), we can estimate from our data, using EUROCAT congenital anomaly prevalence estimates, that an extra 28 cases would be born with major congenital anomalies to these women, of which under half would be cardiac defects. On a population basis, this strongly reinforces the importance of population measures to prevent depressive illness prior to and during pregnancy, to make readily available the choice of non-pharmacological treatments, and to prioritise further research on both depression and antidepressants. On an individual basis, the additional risk of congenital anomaly (approximately $0.5 \%$ ) is very low. These low estimated risks, which should however be considered together with adverse effects of later pregnancy exposures such as poor neonatal adaptation syndrome, newborn pulmonary hypertension and possible neurodevelopmental effects [6], must be balanced for each individual woman against the benefits of choosing SSRI treatment, benefits which can be vital for both mother and baby in case of severe depression [6].

\section{Acknowledgements}


We thank the many people throughout Europe involved in providing and processing information, including affected families, clinicians, health professionals, medical record clerks and registry staff.

\section{Funding}

AW was funded by a University of Ulster Vice Chancellor’s Research Studentship.

EUROCAT is co-funded by the EC, under the framework of the EU Health Programme 2008-2013, Grant Agreement 20102204 (Executive Agency for Health \& Consumers). EUROCAT registries are funded as fully described in Paper 6 of EUROCAT Report 9 EUROCAT Member Registries: Organization and Activities.

\section{Conflict of Interest.}

The congenital anomaly registries and institutions where EG, MKB, DT, BK, VN, MoM, AP, MG, MCA, AR, LA, LdJvdB and HD are employed have previously received funding from Glaxo Smith Kline for a study of safety of antiepileptic lamotrigine use in pregnancy. No author has had any association with or interest in any antidepressant manufacturer in relation to the current study.

\section{References}

[1] Bijl R, Ravelli A, Van Zessen G. Prevalence of psychiatric disorder in the general population: results of the Netherlands Mental Health Survey and Incidence Study (NEMESIS). Soc Psychiatry Psychiatr Epidemiol 1998;33(12):587-595.

[2] Meyer C, Rumpf H, Hapke U, Dilling H, John U. Lifetime prevalence of mental disorders in general adult population. Results of TACOS study. Nervenarzt 2000;71(7):535. 
[3] Alonso J, Angermeyer MC, Bernert S, Bruffaerts R, Brugha TS, Bryson H, et al. Prevalence of mental disorders in Europe: results from the European Study of the Epidemiology of Mental Disorders (ESEMeD) project. Acta Psychiatr Scand 2004;Supplementum(420):21-27.

[4] Jacobi F, Wittchen HU, Holting C, Hofler M, Pfister H, Muller N, et al. Prevalence, comorbidity and correlates of mental disorders in the general population: results from the German Health Interview and Examination Survey (GHS). Psychol Med 2004;34(4):597-612.

[5] Bonari L, Pinto N, Ahn E, Einarson A, Steiner M, Koren G. Perinatal risks of untreated depression during pregnancy. Canadian Journal of Psychiatry 2004;49(11):726-735.

[6] Stein A, Pearson RM, Goodman SH, Rapa E, Rahman A, McCallum M, Howard LM, Pariante CM. Effects of perinatal mental disorders on the fetus and child. Lancet 2014; 384: 1800-19.

[7] Lo WY, Friedman JM. Teratogenicity of recently introduced medications in human pregnancy. Obstet Gynecol 2002 Sep;100(3):465-473.

[8] NICE. Antenatal and postnatal mental health: clinical management and service guidance. London: British Psychological Society and Gaskell; 2007.

[9] Andrade, S., E., Gurwitz JH, Davis RL, Chan KA, et al. Prescription drug use in pregnancy. Obstet Gynecol 2004;191(2):398-407.

[10] Ververs T, Kaasenbrood H, Visser G, Schobben F, de Jong-van den Berg L, Egberts T. Prevalence and patterns of antidepressant drug use during pregnancy. Eur J Clin Pharmacol 2006 Oct;62(10):863-870. 
[11] Ramos E, Oraichi D, Rey E, Blais L, Berard A. Prevalence and predictors of antidepressant use in a cohort of pregnant women. BJOG 2007 Sep;114(9):1055-1064.

[12] Petersen I, Gilbert RE, Evans SJW, Man S, Nazareth I. Pregnancy as a Major Determinant for Discontinuation of Antidepressants: An Analysis of Data From The Health Improvement Network. J Clin Psychiatry 2011 JUL 2011;72(7):979-985.

[13] Cooper WO, Willy ME, Pont SJ. Increasing use of antidepressants in pregnancy. American Journal of Obstetrics and Gynecology 2007;196(6):544e1-544e5.

[14] Charlton R ${ }^{1}$, Jordan S, Pierini A, Garne E, Neville A, Hansen A, Gini R, Thayer D, Tingay K, Puccini A, Bos H, Nybo Andersen A, Sinclair M, Dolk H, de Jong-van den Berg L. Selective serotonin reuptake inhibitor prescribing before, during and after pregnancy: a population-based study in six European regions. BJOG. 2014 Oct 28. doi: 10.1111/1471-0528.13143.

[15] Andrade SE, Raebel MA, Brown J, Lane K, Livingston J, Boudreau D, et al. Use of antidepressant medications during pregnancy: a multisite study. Obstet Gynecol 2008 Feb 2008;198(2):194.e1-194.e5.

[16] Bakker MK, Kolling P, van den Berg PB, de Walle HE, de Jong van den Berg,L.T. Increase in use of selective serotonin reuptake inhibitors in pregnancy during the last decade, a population-based cohort study from the Netherlands. Br J Clin Pharmacol 2008 Apr;65(4):600-606. 
[17] Pastuszak A, Schick-Boschetto B, Zuber C, Feldkamp M, Pinelli M, Sihn S, et al. Pregnancy outcome following first-trimester exposure to fluoxetine (Prozac). J Am Med Assoc 1993;269(17):2246-2248.

[18] Chambers CD, Johnson KA, Dick LM. Birth outcomes in pregnant women taking fluoxetine. New England Journal of Medicine 1996;335(14):1010-1015.

[19] Kulin NA, Pastuszak A, Sage SR, Schick-Boschetto B, Spivey G, Feldkamp M, et al. Pregnancy outcome following maternal use of the new selective serotonin reuptake inhibitors; A prospective controlled multicenter study. J Am Med Assoc 199825 Feb;279(8):609-610.

[20] Simon GE, Cunningham ML, Davis RL. Outcomes of Prenatal Antidepressant Exposure. Am J Psychiatry 2002 December 1;159(12):2055-2061.

[21] Kallen B. Fluoxetine use in early pregnancy. Birth Defects Res B Dev Reprod Toxicol 2004 Dec;71(6):395-396.

[22] GlaxoSmithKline.Preliminary report on bupropion in pregnancy and the occurrence of cardiovascular and major congenital malformation. 2005.

[23] Ban L, Gibson JE, West J, Fiaschi L, Sokal R, Smeet L, Doyle P, Hubbard RB, Tata LJ. Maternal depression, antidepressant prescriptions, and congenital anomaly risk in offspring: a population based cohort study. BJOG 2014; 121:1471-1481.

[24] Davis RL, Rubanowice D, McPhillips H. Risks of congenital malformations and perinatal events among infants exposed to antidepressant medications during pregnancy. Pharmacoepidemiology and Drug Safety 2007;16(10):1086-1094. 
[25] Cole JA, Ephross SA, Cosmatos IS, Walker AM. Paroxetine in the first trimester and the prevalence of congenital malformations. Pharmacoepidemiol Drug Saf 2007 Oct;16(10):1075-1085.

[26] Diav-Citrin O, Shechtman S, Weinbaum D, Wajnberg R, Avgil M, Di Gianantonio E, et al. Paroxetine and fluoxetine in pregnancy: a prospective, multicentre, controlled, observational study. Br J Clin Pharmacol 2008 Nov;66(5):695-705.

[27] Merlob P, Birk E, Sirota L, Linder N, Berant M, Stahl B, et al. Are selective serotonin reuptake inhibitors cardiac teratogens? Echocardiographic screening of newborns with persistent heart murmur. Birth Defects Res A Clin Mol Teratol 2009 Oct;85(10):837-841.

[28] Pedersen LH, Henriksen TB, Vestergaard M, Olsen J, Bech BH. Selective serotonin reuptake inhibitors in pregnancy and congenital malformations: population based cohort study. BMJ 2009 Sep 23;339:b3569.

[29] Reis M, Kallen B. Delivery outcome after maternal use of antidepressant drugs in pregnancy: an update using Swedish data. Psychol Med 2010 Jan 5;40(10):1723-1733.

[30] Kornum JB, Nielsen RB, Pedersen L, Mortensen PB, Norgaard M. Use of selective serotonin-reuptake inhibitors during early pregnancy and risk of congenital malformations: updated analysis. Clin Epidemiol 2010 Aug 9;2:29-36.

[31] Malm H, Artama M, Gissler M, Ritvanen A. Selective serotonin reuptake inhibitors and risk for major congenital anomalies. Obstet Gynecol 2011 Jul;118(1):111-120. 
[32] Colvin L, Slack-Smith L, Stanley FJ, Bower C. Dispensing patterns and pregnancy outcomes for women dispensed selective serotonin reuptake inhibitors in pregnancy. Birth Defects Res A Clin Mol Teratol 2011 Mar;91(3):142-152.

[33] Jimenez-Solem E, Andersen JT, Petersen M, Broedbaek K, Jensen JK, Afzal S, et al. Exposure to selective serotonin reuptake inhibitors and the risk of congenital malformations: a nationwide cohort study. BMJ Open 2012 Jun 18;2(3):10.1136/bmjopen-2012-001148. Print 2012.

[34] Alwan S, Reefhuis J, Rasmussen SA, Olney RS, Friedman JM, National Birth Defects Prevention Study. Use of selective serotonin-reuptake inhibitors in pregnancy and the risk of birth defects. N Engl J Med 2007 Jun 28;356(26):2684-2692.

[35] Louik C, Lin AE, Werler MM, Hernandez-Diaz S, Mitchell AA. First-Trimester Use of Selective Serotonin-Reuptake Inhibitors and the Risk of Birth Defects. N Engl J Med 2007 June 28;356(26):2675-2683.

[36] Bakker MK, Kerstjens-Frederikse WS, Buys CH, de Walle HE, de Jong-van den Berg LT. First-trimester use of paroxetine and congenital heart defects: a population-based casecontrol study. Birth Defects Res A Clin Mol Teratol 2010 Feb;88(2):94-100.

[37] Berard A, Ramos E, Rey E, Blais L, St-Andre M, Oraichi D. First trimester exposure to paroxetine and risk of cardiac malformations in infants: the importance of dosage. Birth Defects Res B Dev Reprod Toxicol 2007 Feb;80(1):18-27. 
[38] Sivojelezova A, Shuhaiber S, Sarkissian L, Einarson A, Koren G. Citalopram use in pregnancy: Prospective comparative evaluation of pregnancy and fetal outcome. Obstet Gynecol 2005 Dec;193(6):2004-2009.

[39] Wen SW, Yang Q, Garner P, Fraser W, Olatunbosun O, Nimrod C, et al. Selective serotonin reuptake inhibitors and adverse pregnancy outcomes. Obstet Gynecol 2006 4;194(4):961-966.

[40] Einarson A, Pistelli A, DeSantis M, Malm H, Paulus WD, Panchaud, Alice, et al. Evaluation of the Risk of Congenital Cardiovascular Defects Associated With Use of Paroxetine During Pregnancy. Am J Psychiatry 2008 June 1;165(6):749-752.

[41] Manakova E, Hubickova L. Antidepressant drug exposure during pregnancy. CZTIS small prospective study. Neuro Endocrinol Lett 2011;32(Suppl 1):53-56.

[42] Klieger-Grossmann C, Weitzner B, Panchaud A, Pistelli A, Einarson T, Koren G, et al. Pregnancy outcomes following use of escitalopram: a prospective comparative cohort study. J Clin Pharmacol 2012 May;52(5):766-770.

[43] Nordeng H, van Gelder MM, Spigset O, Koren G, Einarson A, Eberhard-Gran M. Pregnancy outcome after exposure to antidepressants and the role of maternal depression: results from the Norwegian Mother and Child Cohort Study. J Clin Psychopharmacol 2012 Apr;32(2):186-194.

[44] Reis M, Kallen B. Combined use of selective serotonin reuptake inhibitors and sedatives/hypnotics during pregnancy: risk of relatively severe congenital malformations or 
cardiac defects. A register study. BMJ Open 2013 Feb 19;3(2):10.1136/bmjopen-2012002166. Print 2013.

[45] Vasilakis-Scaramozza C, Aschengrau A, Cabral H, Jick SS. Antidepressant use during early pregnancy and the risk of congenital anomalies. Pharmacotherapy: The Journal of Human Pharmacology and Drug Therapy 2013;33(7):693-700.

[46] Wurst KE, Poole C, Ephross SA, Olshan AF. First trimester paroxetine use and the prevalence of congenital, specifically cardiac, defects: a meta-analysis of epidemiological studies. Birth Defects Res A Clin Mol Teratol 2010 Mar;88(3):159-170.

[47] Myles N, Newall H, Ward H, Large M. Systematic meta-analysis of individual selective serotonin reuptake inhibitor medications and congenital malformations. Aust N Z J Psychiatry 2013 Nov;47(11):1002-1012.

[48] Koren G, Nordeng HME. Selective Serotonin reuptake inhibitors and malformations: case closed? Seminars in Fetal and Neonatal Medicine 2013; 18: 19-22.

[49] Painuly N, Heun R, Painuly R, Sharan P. Risk of cardiovascular malformations after exposure to paroxetine in pregnancy: meta-analysis. The Psychiatrist 2013;37(6):198-203.

[50] Grigoriadis S, VonderPorten EH, Mamisashvili L, Roerecke M, Rehm J, Dennis C, et al. Antidepressant exposure during pregnancy and congenital malformations: is there an association? A systematic review and meta-analysis of the best evidence. J Clin Psychiatry 2013;74(4):e293-e308. 
[51] Skurtveit S, Selmer R, Tverdal A, Furu K, Nystad W, Handal M. Drug exposure: inclusion of dispensed drugs before pregnancy may lead to underestimation of risk associations. J Clin Epidemiol 2013; 66: 964-972.

[52] Olivier JDA, Akerud H, Kaihola H, Pawluski JL, Skalkidou A, Hogberg U, et al. The effects of maternal depression and maternal selective serotonin reuptake inhibitor exposure on the offspring. Frontiers in Clinical Neuroscience 2013;7, 73.

[53] Preskorn, Sheldon H. Clinically relevant pharmacology of selective serotonin reuptake inhibitors. Clinical pharmacokinetics 1997; 32(1): 1-21.

[54] Sadler, T.W. 2011. Selective serotonin reuptake inhibitors (SSRIs) and heart defects: Potential mechanisms for the observed associations. Reproductive Toxicology, 32 (4), 484489.

[55] Choi, D.S., Kellermann, O., Richard, S., Colas, J.F., Bolanos-Jimenez, F., Tournois, C., Launay, J.-. and Maroteaux, L. 1998. Mouse 5-HT2B Receptor-mediated Serotonin Trophic Functions. Annals of the New York Academy of Sciences, 861 (1), 67-73.

[56] Sari, Y. and Zhou, F.C. 2003. Serotonin and its transporter on proliferation of fetal heart cells. International Journal of Developmental Neuroscience, 21 (8), 417-424.

[57] Scialli AR. Paroxetine exposure during pregnancy and cardiac malformations. Birth Defects Res A Clin Mol Teratol 2010 Mar;88(3):175-177.

[58] Bar-Oz B, Einarson T, Einarson A, Boskovic R, O'Brien L, Malm H, et al. Paroxetine and congenital malformations: Meta-Analysis and consideration of potential confounding factors. Clin Ther 2007 5;29(5):918-926. 
[59] Huybrechts KF, Palmsten K, Avorn J, Cohen LS, Holmes LB, Franklin JM, Mogun H, Levin R, Kowal M, Setoguchi S, Hernandez-Diaz S. N Engl J Med 2014; 370:2397-407.

[60] Boyd PA, Haeusler M, Barisic I, Loane M, Garne E, Dolk H. Paper 1: The EUROCAT network-organization and processes. Birth Defects Res A Clin Mol Teratol 2011 Mar;91(Suppl 1):S2-S15.

[61] Jentink J, Loane MA, Dolk H, Barisic I, Garne E, Morris JK, de Jong-van den Berg LTW for the EUROCAT Antiepileptic Drug Working Group. Valproic acid monotherapy exposure in the first trimester of pregnancy and risk of specific birth defects. N Engl J Med. 2010 Jun 10;362(23):2185-93.

[62] Greenlees R, Neville A, Addor MC, Amar E, Arriola L, Bakker M, et al. Paper 6: EUROCAT member registries: organization and activities. Birth Defects Res A Clin Mol Teratol 2011 Mar;91(Suppl 1):S51-S100.

[63] EUROCAT. EUROCAT Guide 1.3 and reference documents. Instructions for the registration and surveillance of congenital anomalies. 2005. http://www.eurocatnetwork.eu/aboutus/datacollection/guidelinesforregistration/guide1_3instructionmanual. Accessed Nov 2014.

[64] Dolk H, Loane M, Garne E and a EUROCAT Working Group. Congenital heart defects in Europe: prevalence and perinatal mortality, 2000 to 2005. Circulation. 2011; 123: 841849.

[65] Garne E, Dolk H, Loane M, Wellesley D, Barisic I, Calzolari E, et al. Paper 5: Surveillance of multiple congenital anomalies: Implementation of a computer algorithm in 
European registers for classification of cases. Birth Defects Research Part A: Clinical and Molecular Teratology 2011;91(S1):S44-S50.

[66] Wellesley D, Boyd P, Dolk H, Pattenden S. An aetiological classification of birth defects for epidemiological research. J Medical Genetics 2005;42(1):54-7.

[67] Rasmussen SA, Olney RS, Holmes LB, Lin AE, Keppler-Noreuil KM, Moore CA, et al. Guidelines for case classification for the National Birth Defects Prevention Study. Birth Defects Research 2003 Mar;67(3):193-201.

[68] Bakker M, De Jonge L. EUROCAT Special Report: Sources of information on medication use in pregnancy. http://www.eurocat-network.eu/content/Special-ReportMedication-Use-In-Pregnancy.pdf. Accessed November 2014.

[69] WHO Collaborating Centre for Drug Statistics Methodology. ATC/DDD Index 2010. 2009; Available at: http://www.whocc.no/atc_ddd_index/. Accessed 04/24, 2010.

[70] Rothman KJ. No adjustments are needed for multiple comparisons. Epidemiology 1990 Jan;1(1):43-46.

[71] Palmsten K, Huybrechts KF, Kowal MK, Mogun H, Hernandez-Diaz S. Validity of maternal and infant outcomes within nationwide Medicaid data. Pharmacoepidemiology and Drug Safety 2014; 23: 646-655.

[72] Carmichael SL, Shaw GM, Yang W, Abrams B, Lammer EJ. Maternal stressful life events and risks of birth defects. Epidemiology 2007 May;18(3):356-361. 
[73] Källén B, Tandberg A. Lithium and pregnancy. A cohort study on manic-depressive women. Acta Psychiatr Scand 1983;68(2):134-9.

[74] Jones I, Chandra P\S, Dazzan P, Howard LM. Bipolar disorder, affective psychosis, and schizophrenia in pregnancy and the post-partum period. Lancet 2014; 384:1789-99.

[75] Torfs CP, Velie EM, Oechsli FW, Bateson TF, Curry CJR. A population-based study of gastroschisis: Demographic, pregnancy, and lifestyle risk factors. Teratology 1994;50(1):4453.

[76] Stothard KJ, Tennant PWG, Bell R, Rankin J. Maternal overweight and obesity and the risk of congenital anomalies. JAMA: The Journal of the American Medical Association 2009;301(6):636-650.

[77] Hackshaw A, Rodeck C, Boniface S. Maternal smoking in pregnancy and birth defects: a systematic review based on 173687 malformed cases and 11.7 million controls. Hum Reprod Update 2011;17(5):589-604.

[78] Martínez-Frías ML, Bermejo E, Rodríguez-Pinilla E, Frías JL. Risk for congenital anomalies associated with different sporadic and daily doses of alcohol consumption during pregnancy: a case-control study. Birth Defects Research Part A, Clinical and Molecular Teratology 2004;70(4):194-200.

[79] Krauss MJ, Morrissey AE, Winn HN, Amon E, Leet TL. Microcephaly: An epidemiologic analysis. Obstet Gynecol 2003 6;188(6):1484-1490.

[80] Johansen RLR, Mortensen LH, Nybo Andersen A-M, Vinkel Hansen A, StrandbergLarsen K. Maternal use of Selective Serotonin Reuptake Inhibitors and Risk of Miscarriage - 
assessing potential biases. Paediatric and Perinatal Epidemiology; 2014: doi:

10.1111/ppe.12160.

[81] Czeizel AE, Puho EH, Acs N, Banhidy F. Use of specified critical periods of different congenital abnormalities instead of the first trimester concept. Birth Defects Research Part A - Clinical and Molecular Teratology 2008 Mar 2008;82(3):139-146. 
Table 1:

Registry, population (births), number of Congenital Anomaly (CA) registrations, and number and \% SSRI exposure

\begin{tabular}{|c|c|c|c|c|c|}
\hline Registry & Birth Years & Births & CA & $\begin{array}{l}\text { SSRI } \\
(\mathrm{N})\end{array}$ & SSRI (\%) \\
\hline Antwerp (Belgium) ${ }^{\mathrm{M}}$ & $2000-2004$ & 61,585 & 1,776 & 5 & 0.30 \\
\hline Basque Country (Spain) ${ }^{\mathrm{M}}$ & 2005-2009 & 103,040 & 1,188 & 8 & 0.70 \\
\hline Cork \& Kerry (Ireland) ${ }^{\mathrm{M}}$ & $1996-2004$ & 71,625 & 1,086 & 10 & 0.90 \\
\hline Malta $^{\mathrm{M}}$ & 1995-1999 & 23,368 & 615 & $1^{\wedge}$ & 0.20 \\
\hline Northern Netherlands ${ }^{\mathrm{M}, \mathrm{I}, \mathrm{P}}$ & 1995-2009 & 288,971 & 5,217 & 53 & 1.00 \\
\hline Norway $^{\mathrm{M}}$ & $2000-2009$ & 590,747 & 15,347 & 82 & 0.50 \\
\hline Odense (Denmark) ${ }^{\mathrm{M}}$ & $2000-2009$ & 53,491 & 932 & 21 & 2.30 \\
\hline Paris (France) ${ }^{\mathrm{M}}$ & $2000-2009$ & 278,435 & 5,104 & 15 & 0.30 \\
\hline $\begin{array}{l}\text { Saxony-Anhalt } \\
(\text { Germany) }\end{array}$ & $2005-2009$ & 86,662 & 1,605 & 7 & 0.40 \\
\hline Tuscany (Italy) ${ }^{\mathrm{I}}$ & $2005-2009$ & 152,137 & 778 & 7 & 0.90 \\
\hline Vaud (Switzerland) ${ }^{\mathrm{M}}$ & 2000-2009 & 73,522 & 1,657 & 6 & 0.40 \\
\hline Wales $(\mathrm{UK})^{\mathrm{M}}$ & 1998-2009 & 394,394 & 7,678 & 113 & 1.50 \\
\hline TOTAL & & $2,177,977$ & 42,983 & 328 & 0.76 \\
\hline
\end{tabular}

$\wedge$ Malta fulfilled inclusion criteria of 5 exposed CA registrations before specific exclusions were made.

${ }^{\mathrm{M}}$ Medication ascertainment from prospective maternal medical/midwifery notes

${ }^{\mathrm{I}}$ Information on medication exposure taken from or confirmed through maternal interviews after birth

${ }^{\mathrm{P}}$ Information available on maternal prescriptions 
Table 2: Number (N) and Odds Ratios (OR) of maternal exposure to SSRIs, combined and by SSRI type, comparing CHD subgroups with controls, 12 EUROCAT registries 1995-2009

\begin{tabular}{|c|c|c|c|c|c|c|c|c|c|c|c|c|c|}
\hline \multicolumn{2}{|l|}{ CA } & \multicolumn{2}{|r|}{ SSRI } & \multicolumn{2}{|c|}{ Fluoxetine } & \multicolumn{2}{|c|}{ Paroxetine } & \multicolumn{2}{|c|}{ Citalopram } & \multicolumn{2}{|c|}{ Sertraline } & \multicolumn{2}{|c|}{ Escitalopram } \\
\hline & $\mathbf{N}$ & $\mathbf{N}$ & $\begin{array}{l}\text { Adj* OR } \\
\text { (95\% CI) }\end{array}$ & $\mathbf{N}$ & $\begin{array}{l}\text { Adj* OR } \\
\text { (95\% CI) }\end{array}$ & $\mathbf{N}$ & $\begin{array}{l}\text { Adj* OR } \\
\text { (95\% CI) }\end{array}$ & $\mathbf{N}$ & $\begin{array}{l}\text { Adj* OR } \\
\text { (95\% CI) }\end{array}$ & $\mathbf{N}$ & $\begin{array}{l}\text { Adj* OR } \\
\text { (95\% CI) }\end{array}$ & $\mathbf{N}$ & $\begin{array}{l}\text { Adj* OR } \\
\text { (95\% CI) }\end{array}$ \\
\hline CHD & 12876 & 108 & $\begin{array}{c}1.41 \\
(1.07-1.86) \\
\end{array}$ & 31 & $\begin{array}{c}1.4 \\
(0.85-2.40) \\
\end{array}$ & 31 & $\begin{array}{c}1.53 \\
(0.91-2.58) \\
\end{array}$ & 23 & $\begin{array}{c}1.45 \\
(0.79-2.65) \\
\end{array}$ & 16 & $\begin{array}{c}1.51 \\
(0.73-3.12) \\
\end{array}$ & 7 & $\begin{array}{c}1.10 \\
(0.41-2.95) \\
\end{array}$ \\
\hline Severe CHD & 2935 & 28 & $\begin{array}{c}1.56 \\
(1.02-2.39)\end{array}$ & 8 & $\begin{array}{c}1.46 \\
(0.66-3.23)\end{array}$ & 6 & $\begin{array}{c}1.08 \\
(0.44-2.63)\end{array}$ & 6 & $\begin{array}{c}1.85 \\
(0.73-4.66)\end{array}$ & 6 & $\begin{array}{c}2.88 \\
(1.09-7.61)\end{array}$ & 2 & $\begin{array}{c}1.65 \\
(0.35-7.81)\end{array}$ \\
\hline Transposition Great Vessels & 615 & 3 & $\begin{array}{c}0.79 \\
(0.25-2.52) \\
\end{array}$ & 0 & - & 1 & - & 0 & - & 1 & - & 1 & - \\
\hline Tetralogy of Fallot & 428 & 8 & $\begin{array}{c}3.16 \\
(1.52-6.58)\end{array}$ & 4 & $\begin{array}{c}5.03 \\
(1.73-14.58)\end{array}$ & 0 & - & 2 & $\begin{array}{c}4.41 \\
(1.02-19.15)\end{array}$ & 1 & $\begin{array}{c}3.33 \\
(0.43-25.68)\end{array}$ & 1 & $\begin{array}{c}5.85 \\
(0.73-47.09)\end{array}$ \\
\hline Atrioventricular Septal Defect & 290 & 4 & $\begin{array}{c}2.08 \\
(0.76-5.73) \\
\end{array}$ & 2 & - & 1 & - & 0 & - & 1 & - & 0 & - \\
\hline Ebstein's anomaly & 93 & 4 & $\begin{array}{c}8.23 \\
(2.92-23.16) \\
\end{array}$ & 0 & - & 1 & $\begin{array}{c}6.43 \\
(0.85-48.54) \\
\end{array}$ & 1 & $\begin{array}{c}12.36 \\
(1.61-95.15) \\
\end{array}$ & 1 & $\begin{array}{c}16.42 \\
(2.10-128.38)\end{array}$ & 1 & $\begin{array}{c}34.19 \\
(4.09-286.04)\end{array}$ \\
\hline Hypoplastic Left Heart & 398 & 3 & $\begin{array}{c}1.22 \\
(0.38-3.88)\end{array}$ & 1 & - & 1 & - & 1 & - & 0 & - & 0 & - \\
\hline Coarctation of aorta & 570 & 4 & $\begin{array}{c}1.12 \\
(0.41-3.07)\end{array}$ & 0 & - & 2 & - & 0 & - & 2 & - & 0 & - \\
\hline Septal defects & 8131 & 64 & $\begin{array}{c}1.36 \\
(0.99-1.87)\end{array}$ & 16 & $\begin{array}{c}1.23 \\
(0.66-2.29)\end{array}$ & 23 & $\begin{array}{c}1.92 \\
(1.09-3.37)\end{array}$ & 9 & $\begin{array}{c}0.88 \\
(0.40-1.94)\end{array}$ & 9 & $\begin{array}{c}1.33 \\
(0.57-3.09)\end{array}$ & 7 & $\begin{array}{c}1.62 \\
(0.60-4.36)\end{array}$ \\
\hline Atrial Septal Defect (ASD) & 2691 & 25 & $\begin{array}{c}1.71 \\
(1.09-2.68) \\
\end{array}$ & 6 & $\begin{array}{c}1.67 \\
(0.68-4.11) \\
\end{array}$ & 5 & $\begin{array}{c}1.38 \\
(0.52-3.69) \\
\end{array}$ & 4 & $\begin{array}{c}1.28 \\
(0.43-3.75) \\
\end{array}$ & 5 & $\begin{array}{c}2.02 \\
(0.71-5.71) \\
\end{array}$ & 5 & $\begin{array}{c}3.31 \\
(1.11-9.90) \\
\end{array}$ \\
\hline ASD without Severe CHD & 2378 & 20 & $\begin{array}{c}1.54 \\
(0.94-2.52)\end{array}$ & 5 & $\begin{array}{c}1.58 \\
(0.60-4.19)\end{array}$ & 5 & $\begin{array}{c}1.65 \\
(0.62-4.42)\end{array}$ & 3 & $\begin{array}{c}1.07 \\
(0.31-3.61)\end{array}$ & 2 & - & 5 & $\begin{array}{c}3.62 \\
(1.21-10.83) \\
\end{array}$ \\
\hline $\begin{array}{l}\text { Ventricular Septal Defect } \\
\text { (VSD) }\end{array}$ & 6167 & 41 & $\begin{array}{c}1.12 \\
(0.77-1.61)\end{array}$ & 10 & $\begin{array}{c}0.97 \\
(0.47-2.02)\end{array}$ & 18 & $\begin{array}{c}1.90 \\
(1.04-3.48)\end{array}$ & 5 & $\begin{array}{c}0.63 \\
(0.24-1.70)\end{array}$ & 6 & $\begin{array}{c}1.15 \\
(0.44-3.01)\end{array}$ & 2 & - \\
\hline VSD without Severe CHD & 5511 & 36 & $\begin{array}{c}1.12 \\
(0.76-1.65)\end{array}$ & 10 & $\begin{array}{c}1.12 \\
(0.54-2.34)\end{array}$ & 17 & $\begin{array}{c}2.12 \\
(1.15-3.92)\end{array}$ & 5 & $\begin{array}{c}0.71 \\
(0.26-1.90)\end{array}$ & 4 & $\begin{array}{c}0.84 \\
(0.27-2.57) \\
\end{array}$ & 0 & - \\
\hline Pulmonary Valve Stenosis & 772 & 7 & $\begin{array}{c}1.30 \\
(0.60-2.83) \\
\end{array}$ & 3 & $\begin{array}{c}1.76 \\
(0.53-5.89) \\
\end{array}$ & 1 & - & 2 & - & 1 & - & 0 & - \\
\hline
\end{tabular}

SSRI use in first trimester pregnancy and risk of congenital anomalies 
Table 3: Number (N) and Odds Ratios (OR) of maternal exposure to SSRIs, combined and by SSRI type, comparing non-CHD signal subgroups with controls, 12 EUROCAT registries 1995-2009

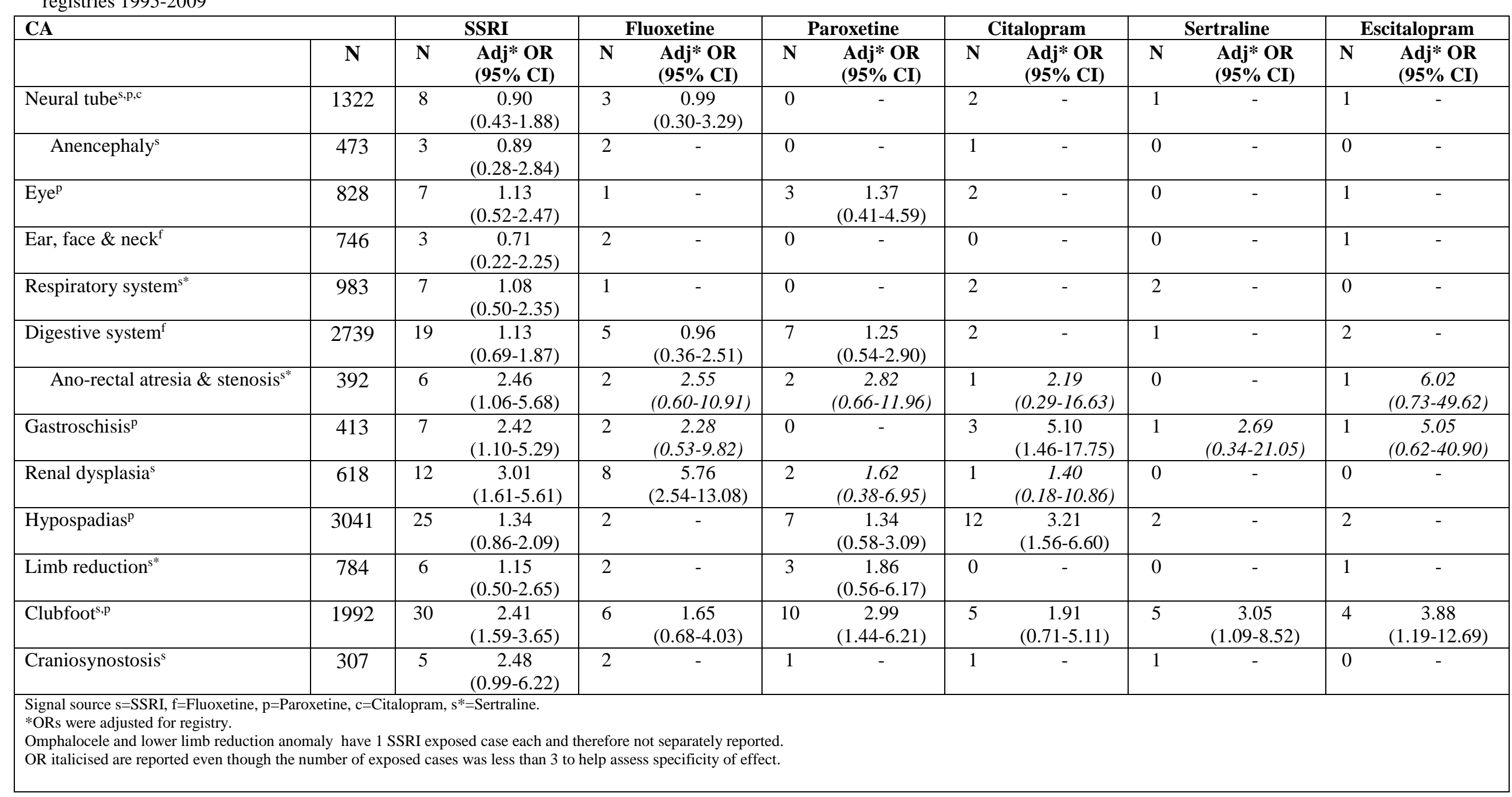

SSRI use in first trimester pregnancy and risk of congenital anomalies 